\title{
REPRODUCTIVE HEALTH ISSUES AMONGST ADOLESCENT FEMALES ATTENDING A HEALTH CENTRE IN RURAL HARYANA: A WAKE UP CALL
}

\author{
Bindoo Yadav1, Aruna Batra ${ }^{2}$, Madhu Egbert ${ }^{3}$
}

${ }^{1}$ Assistant Professor, Department of Obstetrics and Gynaecology, SGT Medical College, Hospital and Research Centre Gurgaon Haryana. 2 Professor, Department of Obstetrics and Gynaecology, SGT Medical College, Hospital and Research Centre Gurgaon Haryana. ${ }^{3}$ SeniorResident, Department of Obstetrics and Gynaecology, SGT Medical College, Hospital and Research Centre Gurgaon Haryana.

ABSTRACT: India's population of over one billion has 21.4\%(243 million) adolescents (10-19 years). In India several programmes have been launched for the adolescents but issues like malnutrition, anaemia, sexually transmitted infections and unwanted pregnancy are still prevalent. This study was carried out to find out the reproductive health issues concerning adolescent girls in rural Haryana and make state specific recommendations for improving the quality of health services for them. 200 adolescent females, who attended the OB-Gynae OPD of a medical college and research centre in rural Haryana, were included in the study. 88(44\%)adolescents were married and there were only $8(4 \%)$ who were married before $18.20 \%$ of the unmarried girls were getting higher education as compared to $10.2 \%$ of the married girls. Married women came for antenatal check-up mostly while unmarried for menstrual irregularities followed by pain abdomen. Anaemia was rampant with $75 \%$ of the girls being anaemic and $3.5 \%$ being severely anaemic. Even though a large number had studied beyond middle school the awareness of STIs/HIV and contraception was poor. Awareness of STIs was found in $15.8 \%$ of married and $12.5 \%$, unmarried,however, only $2.7 \%$ of unmarried had any knowledge of the symptoms and none knew of any method of prevention of STIs. $30.44 \%$ of the unmarried and $29.5 \%$ of the married were aware of HIV/AIDS while only $16.1 \%$ of unmarried and $6.8 \%$ of the married knew about the methods of transmission. None knew that condoms could prevent the transmission. None of the sexually active respondents had used conventional contraception in the past. Logistic regression showed that increase in education increased the awareness regarding STIs and HIV but did not improve the knowledge. For increasing the knowledge of STIs and HIV control and prevention there needs to be a concerted effort in education that requires socio-cultural interventions and integration of steps by various stakeholders such as health, NGOs and education.

KEYWORDS: Female Adolescents, Knowledge, STIs, HIV, Anaemia, Unwanted Pregnancy, Contraception, NFHS3.

HOW TO CITE THIS ARTICLE: Bindoo Yadav, Aruna Batra,Madhu Egbert. "Reproductive Health Issues Amongst Adolescent Females Attending A Health Centre in Rural Haryana: A Wake Up Call”. Journal of Evolution of Medical and Dental Sciences 2015; Vol. 4, Issue 90, November 09; Page: 15502-15507, DOI: 10.14260/jemds/2015/2218.

INTRODUCTION: Adolescence is defined by the UNICEF as "the sequence of events by which the individual is transformed into a young adult by a series of biological changes." This is the span of life between 10 to 19 years, in which the individuals experience changes in body shape, size, functioning and transformation in their behaviour. The global population of adolescents is estimated to continue to increase and to peak just over thirty years from now (UNICEF). India's Population today is over One Billion.

As per Census 2011 there are 236.5 million adolescents (10-19 years) which constitute $19.6 \%$ of India's population. Female adolescents comprise $47 \%$ of adolescent population.(1) Over $31 \%$ of all reported HIV infection in India occurs among 15-24 years.(2) This has been emphasized by Singh and Gururaj who stressed that the problem of high risk sexual behaviour amongst the young needs to be addressed in order to reduce the incidence of STIs including HIV.(3) Gupta in his research papers on adolescent reproductive health in India highlighted that young people are highly vulnerable and majority of them are infected through unprotected sex.(4)

Financial or Other, Competing Interest: None.

Submission 26-10-2015, Peer Review 27-10-2015,

Acceptance 28-10-2015, Published 06-11-2015.

Corresponding Author:

Dr. Bindoo Yadav,

SGT Medical College, Hospital and Research Centre,

Gurgaon, Haryana.

E-mail:abvy90@yahoo.co.in

DOI:10.14260/jemds/2015/2218.
National Family Health Survey (NFHS 3) has highlighted some of the issues regarding the reproductive health of this tender period which will have serious social, economic and public health implications.(5) India was the first country to introduce family planning program as early as early 1950s and yet only 7 per cent of 15-19 year-old are using contraceptive as per the NFHS 3. STIs/RTIs and health-related behaviours acquired during adolescence can leave their impact during adolescence and adulthood and still others like pregnancy and anaemia can have their impact in the next generation.

Adolescents face challenges to their healthy development into adulthood due to a variety of factors lack of information, unfavorable social norms, early marriage, childbearing, and forceful parenting.(6) IIPS in collaboration with Population council, New Delhi conducted a study during 2006-07 in the states of Jharkhand, Bihar, Rajasthan, Maharashtra, Andhra Pradesh and Tamil Nadu in order to find out the issues pertaining to reproductive health practices in youth.

Only $15 \%$ young men and women in 15-24 age group reported that they had received family life or sex education in school or through special program sponsored by the government or NGOs, although they expressed the need for the same. Findings of this study emphasized upon state specific programs as they found each state has different needs.(7)

In view of the above and because Haryana was not included in this study the present study was conducted to delve deeper into this issue in a rural area of Haryana. 
The objective was to study the reproductive health issues concerning adolescent girls and make recommendations for improving the quality of health services to this underserved section of society. It is hoped that the study may be useful in developing policies, activities and programs by the government, non-government organizations and educational institutions.

METHODOLOGY: This retrospective observational study was conducted on 200 adolescent females who attended the OBGynae department of a medical college and research centre in rural Haryana, with some reproductive health complaint, during the period between January 2014 and August 2015and gave an informed written consent to participate in this study. After attending to their presenting complaint, relevant information regarding reproductive and sexual health was obtained through an interview based on structured questionnaire. Confidentiality of the information obtained was assured by the fact that the subjects were identified exclusively by an identification number and interviewed verbally by the chief investigator.

The information obtained included knowledge of STIs, HIV/AIDS and contraception. The responses of the adolescent girls on these issues were analyzed with respect to their education, age and marital status, to determine if these factors contributed to the participants' knowledge. To understand the links between patient characteristics with their responses nonparametric statistics were undertaken.

OBSERVATIONS AND DISCUSSIONS: This study population consisted of 200 adolescent females which included 88 married and 112 unmarried girls. Table 1 depicts the patient characteristics. Most of the adolescents were between 17-19 years of age, even though around $16 \%$ who visited the hospital were below the age of 16 years. Among the married group, all were above 17 years. The mean age of marriage in our study was 18.4 years, and 8 out of 88 married ones (9.1\%) got married before 18 years although they knew that the legal age of marriage in India for girls is 18 years. NFHS 3 reported that $47 \%$ girls in India get married before the age of 18 years.

Majority of the girls had received middle level education, in both the married (74\%) as well as unmarried group (67\%). There was a higher percentage of high school education amongst the unmarried group as compared to the married group (20.5\% vs. $14.8 \%)$. These figures are also better as compared to NFHS 3 report only $28 \%$ of females completing 10 years of schooling

Around $80 \%$ attained menarche at $12-14$ years, with no difference among the married and unmarried groups. The mean age of menarche in this population was 13.44 years, which was comparable to that of $13.6 \pm 0.83$ years reported by Singh et al.(8)

The BMI of the adolescent females varied between 15.8 and 26.7 , with over $80 \%$ girls in both the groups having normal BMI. Only 7.5\% girls had BMI less than 18.5 and $4 \%$ had more than 24.

As per NFHS3nearly half of the females (47\%) in the age group 15-19 are thin. Almost 75\% girls had anemia, of which $40 \%$ had moderate and $3.5 \%$ had severe anemia. NFHS 3 reported nearly $70 \%$ girls between 10-19 yrs suffer from severe to moderate anemia.
Joshi et al reported 95\%of adolescents to be anaemic in their study.(9) Mahavarkar et al have reported that teenage mothers have three times more risk of developing anemia.(10)

Table 2 lists out the reasons for hospital visit by the adolescents. Amongst the married adolescents 57.9\% came for Antenatal checkup. One woman was brought by her in-laws for inability to conceive just after 15 months of married life. Amongst the unmarried girls, menstrual complaints were the commonest reasons to visit the hospital followed by pain abdomen, vaginal discharge, itching vulva and breast complaints. Four girls suffered from secondary amenorrhea due to causes other than pregnancy. None of these had Polycystic Ovarian Disease based on Rotterdam's criteria. Three girls had come with primary amenorrhea for further evaluation.

Table 3 gives the outcome of the pregnancy in the pregnant married adolescents. Of the 88 married women in the study, 51 visited hospital for pregnancy. Thirty nine women came to the hospital for ANC checkup while 12 came in active labor without any prior checkup or booking in the hospital. There were 3 unmarried pregnant adolescents of which 2 came desiring abortion while one came after failed self-induced abortion. While most were primigravidae three women had undergone spontaneous abortions before. All the respondents knew about the total duration of pregnancy. They were only concerned about getting Ultra sonography as a part of the antenatal check-up.

They were not aware about the need for increase in caloric intake or taking regular haematinics. All of them had received injection tetanus toxoid. Moderate to severe anaemia was detected in 14 women. Sixteen out of 53(32\%) women had three visits with regular checkup, 12 had none and 25 had irregular visits in various hospitals. None of them were sure about the birth plan. The birth plan was to be decided by the in-laws and by the family traditions.

None of them had made any contraception plan for spacing. Out of the 53 pregnant married adolescents 23 delivered and 3had spontaneous abortions during the study period. Out of these one developed PIH and another eclampsia. Fifteen women had normal delivery and $8(31 \%)$ had instrumental or caesarean section. Low birth weight babies were born to 6 adolescents.

As per World Bank the "Adolescent fertility rate" of India is coming down from 36 in 2010 to 26 births per 1000 women in 2014. NFHS-3 data revealed that $16 \%$ of women, aged 15-19 years, have already started childbearing. NFHS 3 has shown that more than $75 \%$ of pregnant women in India received at least some antenatal care (ANC), but only half of women have at least three ANC visits with a health provider during their pregnancy, as recommended. Mukhopadhaya et al reported that teenage have higher incidence of preterm and low birth weight babies.(11)

Knowledge regarding STI/HIV is given in Table 4. Twenty seven adolescents were aware of STIs and the majority of respondents (197 out of 200) had no knowledge about the signs and symptoms of sexually transmitted infections.

Similar disturbing findings were given by McManus and Dhar et al.(12) Some reported breast pain (7 out of 200) as symptoms of STIs in women.

When asked about HIV/AIDS 60 were aware of it but only 23 knew that it could be sexually transmitted. Surprisingly more adolescents had heard of the term AIDS as compared to term HIV.

Even among the antenatal women who were booked and had undergone HIV testing many were not aware that HIV 
transmission could be prevented or that it could be transmitted to the unborn child from an affected mother. Seven of these women felt that this was a kind of blood test. They were not concerned about the reason for getting it done. Findings from NFHS 3 on the extent and sex differentials in knowledge of HIV/AIDS show that only $84 \%$ of men and $61 \%$ of women have ever heard of AIDS.

The main sources of information available to respondents about HIV/AIDS, other STIs and safe sex were school (23), TV (22), friends (6), the media (4), books/magazines (4) and the Internet (1). Only 7 girls had discussed these issues with their mothers or sisters. This was despite the fact that $18 \%$ of the girls were studying in 12 th standard or were in college and $70 \%$ had studied beyond $8^{\text {th }}$ standard. Some adolescent girls expressed the need of a clinic for them in the late afternoon so that the classes are not missed and which will cater to them only. They felt that this will improve their access to health services. They further expressed that teachers hesitate to discuss the reproductive health issues with them.

Logistic regression regarding the awareness of HIV/AIDS with age, education and marital status as the predictors revealed that the model was statistically significant Age and education of the participants were the significant contributors to the model such that 1 unit increase in age of the respondents leads to an increase in the odds of having heard of HIV 1.57 and the 1 unit increase in education of the respondents leads an increase in the odds of havingheard of HIV by 1.65 (See Table 4). Also age and education of the participants were significant contributors to the model regarding knowledge about the methods of spread of HIV, such that 1 unit increase in age of the respondents leads to an increase in the odds of having knowledge of HIV by 2.06 and the 1 unit increase in education of the respondents leads to the odds of an increase in knowledge of HIV by 1.48. (Table 4)

Regarding the awareness of STIs with age, education and marital status as the predictors Education of the participants was significant contributors to the model such that 1 unit increase in education of the respondents led to increase in the odds of having heard of STI by 1.44. Regarding the knowledge of any symptoms of STIs and their, prevention none of the predictors were significant and hence logistic regression could not be completed (Table 4).

Similarly regarding the knowledge of contraception, none of the predictors were significant. Hence logistic regression could not be completed. Knowledge of contraception for spacing was limited to only 27 women out of $200(13.5 \%)$ and they had heard of a few contraceptives. Only five women gave history of premarital sex. None of the respondents had used routine contraception in the past even though $91(49.5 \%)$ were sexually active adolescents.

Three women out of the 56 pregnant women did say that the present pregnancy was not wanted by her or her husband but they had neither the choice nor any means to use a method of contraception correctly. There was pressure on them by the in-laws to have a child soon.

The husbands of these women too were not aware of contraception.
Infact these adolescent married women expressed that the men should be made aware of conventional methods of contraception so that pregnancy can be planned. As per NFHS3 nearly two-thirds of married women are not aware that usage of condoms can help in preventing transmission of. NACO updates 2005 stated that $32 \%$ of AIDS cases reported in India affect the youth and the number of young women living with HIV/AIDS is twice that of young men.(2) As women are also more susceptible than men this becomes an area of great concern because ignorance can increase their chance of acquiring STI/HIV.(13)

Likewise none of the adolescents in the study had heard of or were aware of any vaccination against HPV.

In the NFHS3, it is mentioned that more than half of married girls between 15-24 years wanted to delay the first pregnancy, $17 \%$ of $15-24$ year old married girls stated that their last pregnancy was mistimed or unwanted, but just $10 \%$ actually practiced contraception.

As per NFHS3, the unmet need for family planning is higher among $15-19$ year-olds at $27 \%$ compared to $13 \%$ unmet need across all age groups as only 7 per cent of 15-19 year-old are using contraceptive. Gupta et al have stated that it is the society which dictates that the girls marry young and have a child soon after.(14) Besides this the women get secure in the home of their in-laws only after the birth of a son.(15) An infertile married woman risks being rejected by her in-laws family.(16)

The social pressure to bear a child soon after marriage is a deterrent to the usage of contraceptives soon after marriage. As per Nair, less than $10 \%$ of adolescents use contraception and they have misconceptions about health effects of contraceptives, including their future ability to bear children. Hence they do not resort to contraception and get pregnant soon after.(17) This has been previously reported by Shah et al.(18)Findings from NFHS3 suggest that age-specific fertility rate in the age group of 15-19 years contributes to $17 \%$ per cent of the total fertility rate.

Emergency methods of contraception were known to 16 participants. Only one unmarried girl reported that she had used emergency contraception. Two unmarried girls came asking for abortions while one came following unsafe abortion. Five (2.5\%) adolescents gave a history of premarital sex, however, they were not aware of how to protect themselves from STIs or unwanted pregnancy. As per McManus and Dhar evidence shows increasing incidence of premarital sex.(12) NFHS 3 report states that $4 \%$ of adolescent girls or young women had pre-marital sex.

We found that education is a strong factor in increasing the knowledge regarding HIV. Kumaraswamy et al reported that education is essential for the young people to make decisions regarding contraception and prevention of STIs.(19)

On the other hand Nair in one editorial pointed out that a higher level of knowledge about contraception, however, does not always translate into a higher level of contraceptive use. He gave the example of India and Nepal, where he reported high level of knowledge of contraception yet less than $10 \%$ of adolescent girls were found to be using any form of contraceptive in these two countries. ${ }^{(10)}$

This has been reiterated by Kapoor et al.(19) If these problems are neglected then the energy and creativity of this mammoth group will be lost and a huge resource will be drained out.(14) This gap between knowledge and practice has emerged as a great barrier in reducing the menace of STIs/unwanted pregnancy and anemia in this underserved group of society. 
Limitation of the Study: This study included only those adolescents females who had attended the hospital with some reproductive health complaint in OPD of OB-Gynae department of the hospital .

CONCLUSION: This study of the reproductive health issues amongst female adolescents in rural Haryana showed that the level of education and nutrition was good as compared to the NFHS3 reports. It also revealed that most women got married above 18years. The general health was better and severe anaemia was less. Awareness regarding STIs/HIV was present however knowledge was lacking. As per WHO adolescents need information, skills, safe \& supportive environment, health \& counselling services. However Wellinger has mentioned that there can be no single intervention which will be a solution for all.(21)

To tackle these burning issues there is need for integration of different departments of health services and social factors. Setting up of adolescent clinics and help lines can help in improving the reproductive health of this group. By organizing Health melas in all the medical colleges of the country for the school going children (Both boys and girls) between classes $6-11^{\text {th }}$ standard the children will be provided with correct information and knowledge about these issues. Even the teachers accompanying them can also correct their doubts and misconceptions.

It is suggested that the teachers may be involved in workshops pertaining to reproductive health issues so that they can communicate with the students by way of role play and problem solving exercises. Exhibitions for the local leaders, panchayat members at the district level especially in the hospitals showcasing the avenues available for the adolescents regarding reproductive health may help in bring about some social change.

\section{REFERENCES:}

1. Census India SRS Bulletin. Registrar general of India, Govt. of India 2011.

2. NACO: monthly updates on AIDS 2005.

3. Singh Sunitha \& Gopal Krishna Gururaj: Health behaviours \& problems among young people in India: Cause for concern \& call for action, Indian J Med Res 140, August 2014, pp 185-208.

4. Gupta, S.D Adolescent Reproductive Health in India status policies programs and issues. Washington, DC: Policy Project, 2003.

5. International Institute for Population Sciences. National Family Health Surveys. Key findings 1998-1999 and 20052006. International Institute for Population Sciences, Mumbai IIPS NFHS3.

6. MOHFW (2006): Implementation guide in RCH II adolescent re- productive sexual health strategy for state and district programme managers. New Delhi: Ministry of Health and Family Welfare, GoI.
7. MOHFW : Situation and Needs2006-2007, youth in India2006.Government Of India Ministry of Health \& Family Welfare Nirman Bhawan, New Delhi - 110011.

8. Singh et al: Awareness and health seeking behaviour of rural adolescent school girls on menstrual and reproductive health problems, Indian journal of medical sciences Year:1999|Volume: 53|Issue:10|Page:439-443.

9. Joshi et al: Reproductive Health Problems and Help Seeking Behavior Among Adolescents in Urban India Indian Journal of Pediatrics, Volume 73-June, 2006.

10. Mahavarkar S. H., Madhu C. K. Mule V. D : A comparative study of teenage pregnancy,Journal of Obstetrics and Gynaecology, Volume 28, Issue 6, 2008.

11. Mukhopadhyay P., Chaudhuri R N, Paul B. Hospital-based perinatal outcomes and complications in teenage pregnancy in India, Health PopulNutr. 2010 Oct; 28(5): 494-500.

12. McManus and Dhar: Study of knowledge, perception and attitude of adolescent girls towards STIs/HIV, safer sex and sex education: A cross sectional survey of urban adolescents school girls in South Delhi, India. BMC women's Health 2008,8:12doi:10.1186/1472-6874-8-12

13. UNFPA: Sexually Transmitted Infections: Breaking The Cycle of Transmission. New York: United Nations Population Fund; 2004.

14. Gupta M, Ramani K. V. Soors Werner: Adolescent Health in India: Still at Crossroads Advances in Applied Sociology 2012. Vol.2, No.4, 320-324 Published Online December 2012 in SciRes (http://www.SciRP.org/journal/aasoci)

15. JejeebhoyS. J. (1998). Adolescent sexual and reproductive behaviour: A review of the evidence from India. Social Science \& Medicine, 46, pp. 1275-1290. doi:10.1016/S02779536(97)10056-9

16. Park K. Park's textbook of preventive and social medicine, pp. 546, Jabalpur, M/S BanarsidasBhanot, Publishers, 21st edition.

17. Nair, MKC: Adolescent Sexual and Reproductive Health. www.indianpractices .net/jan2004/jan-7-13.htm Editorial. Indian Pediatrics 2004; 41:7-13

18. Shah et al: Attitudes of Adolescent Girls Towards Contraceptive Methods: Australas MedJ. 2011;4(1):43-8. doi: 10.4066/AMJ.2011.499. Epub 2011 Jan 31

19. Kumaraswamy $\mathrm{N}$ et al :Natural history of human immunodeficiency virus disease in southern India.Clinical Infectious diseases 2003,36:79-85.PubMed

20. Kapoor Rajat, Kishore Jugal and Gupta N:Awareness about contraceptive practices among youths in Delhi, 31 (1): 52-62, 2008, Health and Population Perspectives and Issues

21. Wellings K: Sexual behaviour in context: a global perspective. The Lancet Sexual and Reproductive Health Series, October 2006 ,www.who.int/reproductive health/publications /general/lancet_2.pdf. 


\begin{tabular}{|c|c|c|c|c|c|c|}
\hline \multirow[b]{2}{*}{$\mathrm{V}$} & \multicolumn{2}{|c|}{$\begin{array}{c}\text { Married } \\
(\mathrm{N}=88)\end{array}$} & \multicolumn{2}{|c|}{$\begin{array}{c}\text { Unmarried } \\
(\mathrm{N}=112)\end{array}$} & \multicolumn{2}{|c|}{$\begin{array}{c}\text { Total } \\
(\mathrm{N}=200)\end{array}$} \\
\hline & No. & $\%$ & No. & $\%$ & No. & $\%$ \\
\hline \multicolumn{7}{|l|}{ Age group } \\
\hline $10-13$ & 0 & 0 & 6 & 5.4 & 6 & 3.0 \\
\hline $14-16$ & 0 & 0 & 25 & 22.3 & 25 & 12.5 \\
\hline $17-19$ & 88 & 100 & 81 & 72.3 & 169 & 84.5 \\
\hline \multicolumn{7}{|l|}{ Education (standard) } \\
\hline$\leq$ Primary & 10 & 11.4 & 14 & 9.8 & 24 & 12.0 \\
\hline Middle & 65 & 73.8 & 75 & 66.9 & 140 & 70.0 \\
\hline$\geq$ High School & 13 & 10.2 & 23 & 20.5 & 36 & 18.0 \\
\hline \multicolumn{7}{|c|}{ Age at menarche (Yrs) } \\
\hline$<12$ & 6 & 6.8 & 10 & 8.9 & 16 & 6.5 \\
\hline $12-13$ & 42 & 47.7 & 39 & 34.8 & 81 & 41.5 \\
\hline $13-14$ & 31 & 35.2 & 50 & 44.6 & 81 & 41.5 \\
\hline $14-15$ & 9 & 10.2 & 10 & 8.9 & 19 & 9.5 \\
\hline Not attained & 0 & 0 & 3 & 2.7 & 3 & 1.5 \\
\hline \multicolumn{7}{|l|}{ Haemoglobin(gm/dl) } \\
\hline Normal $(>11)$ & 19 & 21.6 & 30 & 26.7 & 49 & 24.5 \\
\hline Mild (10-11) & 28 & 31.8 & 34 & 30.4 & 62 & 31.0 \\
\hline Moderate (7-10) & 38 & 43.2 & 44 & 39.3 & 82 & 41.0 \\
\hline Severe $(<7)$ & 3 & 3.4 & 4 & 3.6 & 7 & 3.5 \\
\hline \multicolumn{7}{|l|}{ BMI } \\
\hline$<18.50$ & 6 & 6.8 & 9 & 8.0 & 15 & 7.5 \\
\hline$(18.5-24)$ & 81 & 81.0 & 96 & 85.7 & 177 & 88.5 \\
\hline$>24$ & 1 & 1.1 & 7 & 6.3 & 8 & 4.0 \\
\hline
\end{tabular}

\begin{tabular}{|c|c|c|c|c|c|c|}
\hline \multirow[t]{2}{*}{ Complaints } & \multicolumn{2}{|c|}{$\begin{array}{c}\text { Married } \\
(\mathrm{N}=88)\end{array}$} & \multicolumn{2}{|c|}{$\begin{array}{c}\text { Unmarried } \\
(\mathrm{N}=112)\end{array}$} & \multicolumn{2}{|c|}{$\begin{array}{c}\text { Total } \\
(\mathrm{N}=\mathbf{2 0 0})\end{array}$} \\
\hline & No. & $\%$ & No. & $\%$ & No. & $\%$ \\
\hline Antenatal checkup & 51 & 58.0 & 0 & 0 & 51 & 25.5 \\
\hline Menstrual complaints & 12 & 13.6 & 42 & 37.5 & 54 & 27.0 \\
\hline Vaginal discharge & 8 & 8.9 & 20 & 17.85 & 28 & 14 \\
\hline Itching vagina & 3 & 3.4 & 5 & 4.46 & 8 & 4.0 \\
\hline Pain abdomen & 9 & 10.2 & 32 & 28.6 & 41 & 20.5 \\
\hline $\begin{array}{l}\text { Urinary Tract } \\
\text { Infection }\end{array}$ & 3 & 3.4 & 3 & 2.7 & 6 & 3.0 \\
\hline Abortion & 0 & 0 & 3 & 2.7 & 3 & 1.5 \\
\hline Infertility & 1 & 1.1 & 0 & 0 & 1 & 0.5 \\
\hline Others & 1 & 1.1 & 7 & 6.2 & 8 & 4.0 \\
\hline
\end{tabular}




\begin{tabular}{|c|c|c|}
\hline & \multicolumn{2}{|c|}{$\begin{array}{l}\text { Married Pregnant Adolescents } \\
\qquad(\mathrm{N}=51)\end{array}$} \\
\hline & No. & $\%$ \\
\hline \multicolumn{3}{|l|}{ Gravida } \\
\hline Primi & 48 & 94.11 \\
\hline 1 previous abortion & 3 & 5.7 \\
\hline \multicolumn{3}{|l|}{ Antenatal Visits } \\
\hline Regular & 14 & 27.45 \\
\hline Irregular & 25 & 49.01 \\
\hline None(came in Labor) & 12 & 23.52 \\
\hline \multicolumn{3}{|l|}{ Outcome(during study period) } \\
\hline Abortion (spontaneous/missed) & 03 & 5.88 \\
\hline Delivered & 23 & 45.09 \\
\hline Undelivered & 25 & 49.01 \\
\hline PE/Eclampsia & 02 & 3.92 \\
\hline \multicolumn{3}{|l|}{ Mode of delivery } \\
\hline Normal Vaginal & 15 & 65.2 \\
\hline Instrumental Delivery & 2 & 8.7 \\
\hline LSCS & 6 & 26.1 \\
\hline \multicolumn{3}{|l|}{ POG at Delivery } \\
\hline Abortion (spontaneous/missed) & 3 & 5.88 \\
\hline Preterm & 3 & 13.04 \\
\hline Term & 17 & 73.91 \\
\hline Post term & 3 & 13.04 \\
\hline \multicolumn{3}{|l|}{ Baby Weight } \\
\hline$<2500 \mathrm{gm}$ & 6 & 26.1 \\
\hline $2500-4000 \mathrm{~g}$ & 17 & 73.9 \\
\hline$>4000 \mathrm{~g}$ & 0 & 0.0 \\
\hline
\end{tabular}

\begin{tabular}{|c|c|c|c|c|c|c|c|}
\hline & \multicolumn{2}{|c|}{ Married } & \multicolumn{2}{|c|}{ Unmarried } & \multicolumn{2}{|c|}{ Total } & \multirow{2}{*}{$\begin{array}{c}\text { Logistic } \\
\text { regression } \\
\text { with age, } \\
\text { education, } \\
\text { marital } \\
\text { status as } \\
\text { predictors }\end{array}$} \\
\hline STIs & $\begin{array}{l}\text { Yes no. } \\
(\%)\end{array}$ & $\begin{array}{l}\text { No no. } \\
(\%)\end{array}$ & $\begin{array}{c}\text { Yes no. } \\
(\%)\end{array}$ & $\begin{array}{c}\text { No no. } \\
(\%)\end{array}$ & $\begin{array}{c}\text { Yes no. } \\
(\%)\end{array}$ & $\begin{array}{c}\text { No. no. } \\
(\%)\end{array}$ & \\
\hline $\begin{array}{c}\text { Awareness of } \\
\text { STIs }\end{array}$ & $\begin{array}{c}13 \\
(15.8)\end{array}$ & 75 (85.2) & $\begin{array}{c}14 \\
(12.5)\end{array}$ & $\begin{array}{c}98 \\
(87.5)\end{array}$ & $\begin{array}{c}27 \\
(13.5)\end{array}$ & $\begin{array}{c}173 \\
(86.5)\end{array}$ & $\begin{array}{c}<<0.01 \text {, Chi sq. } \\
11.6(199,3), \\
\text { Accuracy } 76 \%\end{array}$ \\
\hline $\begin{array}{l}\text { Knowledge of } \\
\text { symptoms }\end{array}$ & 0 & $\begin{array}{c}88 \\
(100)\end{array}$ & $3(2.7)$ & 109 (97.3) & $\begin{array}{c}3 \\
(1.5)\end{array}$ & $\begin{array}{c}197 \\
(98.5)\end{array}$ & $\begin{array}{l}\text { None of the } \\
\text { predictors was } \\
\text { significant }\end{array}$ \\
\hline $\begin{array}{l}\text { Knowledge of } \\
\text { prevention }\end{array}$ & 0 & $\begin{array}{c}88 \\
(100)\end{array}$ & 0 & $112(100)$ & 0 & $\begin{array}{c}200 \\
(100)\end{array}$ & \\
\hline \multicolumn{8}{|l|}{ HIV/AIDS } \\
\hline $\begin{array}{c}\text { Awareness of } \\
\text { HIV/AIDS }\end{array}$ & $26(29.5)$ & $62(70.5)$ & $\begin{array}{c}34 \\
(30.4)\end{array}$ & $\begin{array}{c}78 \\
(69.6)\end{array}$ & $\begin{array}{c}60 \\
(30.0)\end{array}$ & $\begin{array}{c}140 \\
(70.0)\end{array}$ & $\begin{array}{c}\mathrm{P}<0.0001, \text { hi } \\
\text { sq. } 41.5 \\
(199,3), \\
\text { Accuracy } 76 \%\end{array}$ \\
\hline $\begin{array}{l}\text { Knowledge of } \\
\text { spread }\end{array}$ & $\begin{array}{c}6 \\
(6.8)\end{array}$ & $82(93.2)$ & $\begin{array}{c}18 \\
(16.1)\end{array}$ & $\begin{array}{c}94 \\
(84.0)\end{array}$ & $\begin{array}{c}24 \\
(12.0)\end{array}$ & $176(88.0)$ & $\begin{array}{c}\mathrm{P}<0.0001, \text { Chi } \\
\text { sq. 19.8 } \\
(199,3), \\
\text { Accuracy 76\% }\end{array}$ \\
\hline $\begin{array}{l}\text { Knowledge of } \\
\text { prevention }\end{array}$ & 0 & $88(100)$ & 0 & 112 100) & 0 & $200(100)$ & \\
\hline \multicolumn{8}{|l|}{ Contraception } \\
\hline $\begin{array}{l}\text { Awareness of } \\
\text { methods }\end{array}$ & $\begin{array}{c}29 \\
(33.0)\end{array}$ & $59(67.0)$ & $42(37.5)$ & $\begin{array}{c}70 \\
(62.5)\end{array}$ & $\begin{array}{c}71 \\
(35.5)\end{array}$ & $129(64.5)$ & \multirow{2}{*}{$\begin{array}{l}\text { None of the } \\
\text { predictors was } \\
\text { significant }\end{array}$} \\
\hline $\begin{array}{l}\text { Awareness of } \\
\text { Emergency } \\
\text { Contraception }\end{array}$ & $2(2.3)$ & 86 (97.7) & $14(12.5)$ & 98 (87.5) & $16(8.0)$ & $184(92.0)$ & \\
\hline
\end{tabular}

